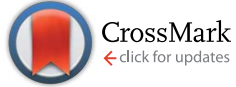

Cite this: J. Anal. At. Spectrom., 2015, 30, 2541

Received 6th August 2015

Accepted 16th October 2015

DOI: $10.1039 / \mathrm{c} 5 \mathrm{ja} 00325 \mathrm{c}$

www.rsc.org/jaas

\title{
Speciation of chromium by dispersive liquid-liquid microextraction followed by laser-induced breakdown spectrometry detection (DLLME-LIBS)
}

\begin{abstract}
Ivanise Gaubeur, ${ }^{\star a}$ Miguel Ángel Aguirre, ${ }^{\mathrm{b}}$ Nikolay Kovachev, ${ }^{\mathrm{b}}$ Montserrat Hidalgo*b and Antonio Canals ${ }^{\mathrm{b}}$

In this study, an analytical methodology based on a combination of dispersive liquid-liquid microextraction with laser-induced breakdown spectrometry was evaluated for simultaneous pre-concentration, speciation and detection of $\mathrm{Cr}$. The microextraction procedure was based on the injection of appropriated quantities of 1-undecanol and ethanol into a sample solution containing the complexes formed between $\mathrm{Cr}(\mathrm{VI})$ and diethyldithiocarbamate (DDTC). The main experimental factors affecting the complexation and the extraction of metal $(\mathrm{pH}$, DDTC concentration, extractant and volume of disperser solvents) were optimized using a multivariate analysis consisting of two steps: a Plackett-Burman design followed by a Circumscribed Central Composite Design (CCCD). Under optimum microextraction conditions, the analytical figures of merit of the proposed methodology were assessed. The method was finally applied to the analysis of a certified reference material hard drinking water (ERM $®$ CA011a), yielding results in good agreement with the certified value.
\end{abstract}

\section{Introduction}

Nowadays, it is widely known that the mobility, bioavailability and toxicity of trace metals in environmental systems not only depend on their concentrations, but critically on their chemical form. Among the various metals in the environment, for instance in soils or superficial and underground water, which may pose toxicity to mankind, we can find chromium. Due to the use of this element in a number of products and industrial activities (e.g. pigments, leather dyeing, electrotyping, wood preservation, and catalysts), it can be dispersed into the environment, causing serious damage. ${ }^{1-5}$

Chromium can be found in two main forms, trivalent and hexavalent. $\mathrm{Cr}(\mathrm{III})$ is an essential trace element and is widely used in nutritional supplements as it plays an important role in maintaining living organisms, for example, controlling glucose as well as being involved in the metabolism of lipids and proteins. ${ }^{3,4}$ However, studies have shown that some $\mathrm{Cr}(\mathrm{III})$ compounds may have genotoxic effects on cell cultures under certain conditions. ${ }^{6} \mathrm{Cr}(\mathrm{vI})$ is considered much more toxic than $\mathrm{Cr}(\mathrm{III})$ and is classified as a carcinogenic element. ${ }^{7}$ The main effects associated with the primary exposure of $\mathrm{Cr}(\mathrm{vI})$

\footnotetext{
${ }^{a}$ Human and Natural Sciences Center - Federal University of ABC, Av. dos Estados, 5001, 09210-971, Santo André, São Paulo,Brazil. E-mail: ivanise.gaubeur@ufabc. edu.br; Tel: +551149960187

${ }^{b}$ Department of Analytical Chemistry and Food Science and University Materials Institute - University of Alicante, Apdo. 99, Alicante E-03080, Spain. E-mail: montserrat.hidalgo@ua.es
}

compounds are respiratory, gastrointestinal, immunologic, hematologic, reproductive and developmental. The difference between toxicological effects from $\mathrm{Cr}(\mathrm{III})$ and $\mathrm{Cr}(\mathrm{VI})$ is rather complex and is also related to the chemical characteristics of each species such as the high oxidation potential of $\mathrm{Cr}(\mathrm{vI})$, as well as the stability, mobility and bioavailability of such species in the environment. In addition, the permeability of $\operatorname{Cr}(\mathrm{vI})$ in cells is greater than that of $\mathrm{Cr}(\mathrm{III}){ }^{8-10}$

Based on the above mentioned discussion, analytical measurements expressed as total metal content in different aquatic, terrestrial or aerial environments appear to be insufficient for proper assessment of the environmental risk of potentially dangerous species. The rapidly growing interest in the elucidation of the chemical forms, in addition to the quantitative estimation of specific elements, has resulted in the development of a new generation of analytical methodologies that are able to perform what is defined as speciation analysis. Hyphenation of chromatographic or extraction techniques, for species separation, with spectrometric techniques is the usual analytical strategy for speciation analysis, and among the different spectrometric techniques, inductively coupled plasma mass spectrometry (ICP-MS), inductively coupled plasma optical emission spectrometry (ICP-OES), and electrothermal atomic absorption spectrometry (ETAAS) are most widely employed. ${ }^{10-12}$ To date, very limited studies have been focused on the use of Laser-Induced Breakdown Spectrometry (LIBS) for speciation analysis. ${ }^{13}$

Among the various procedures used for extraction and preconcentration of metals, aiming at speciation for later detection, we can indicate dispersive liquid-liquid microextraction 
(DLLME), which consists of the rapid injection of a mixture of extractant and disperser solvents into a sample solution. This procedure results in the formation of a cloudy solution, in which fine droplets of the extractant solvent are dispersed in the sample, thus making it possible to carry out both extraction and preconcentration within a rapid single stage. ${ }^{14}$ In addition to its rapidity and simplicity, the use of very small organic solvent volumes in DLLME represents an added advantage over conventional liquid-liquid extraction methodologies, because it makes the procedure less harmful to the environment, with reduced generation of residue, resulting in a reduction in the cost and time devoted to related analysis.

In this study, the speciation of chromium in water samples by combination of DLLME with LIBS is presented for the first time. The analytical methodology evaluated here is based on the selective complexation of $\mathrm{Cr}(\mathrm{vI})$ with diethyldithiocarbamate (DDTC) in acidic medium, followed by the extraction of $\mathrm{Cr}(\mathrm{vI})$ chelates in 1-undecanol using a DLLME procedure. The resulting microvolumes of the analyte-enriched organic solvent are finally analyzed by LIBS. The total Cr content is obtained using the same procedure, after previous oxidation of $\mathrm{Cr}$ species in the sample. Experimental factors affecting the chelation and extraction of $\mathrm{Cr}(\mathrm{vI})$ were optimized using a multivariate approach. Finally, the proposed methodology was applied to the quantification of $\mathrm{Cr}$ in a certified reference material, to assess the analytical capabilities of the method.

\section{Experimental}

\subsection{Instrumentation}

The sample, reagents and final solutions were weighed using an analytical balance (model AX423, Sartorius, Madrid, Spain). A $\mathrm{pH}$ meter with a combined glass electrode was used for $\mathrm{pH}$ measurements. A centrifuge (model 2690/5, Nahita Centrifuges, Beriain, Spain) was used to accelerate the phase separation. The disperser and extractant solvent mixture was injected into the sample using a $1000 \mu \mathrm{L}$ syringe (Gastight ${ }^{\circledR}$, Hamilton Co, Reno, Nevada, USA).

For LIBS analysis, the laser-induced plasmas were generated in air at atmospheric pressure by focusing a $10 \mathrm{~Hz}$ pulsed Nd-YAG laser (model HYL101 Handy-YAG, Q-switched, Quanta System S.P.A., Varese, Italy) on the sample to analyze it. The laser was operated in single-pulse mode, emitting at its fundamental wavelength (i.e. $1064 \mathrm{~nm}$ ) with energy $130 \mathrm{~mJ}$ per pulse and $10 \mathrm{~ns}$ FWHM pulse width. The laser beam was focused on the samples using a N-BK7 plano-convex lens with $100 \mathrm{~mm}$ focal length (model KPX094AR.33, Newport Corporation, Irvine, USA). Plasma emission was directly collected with a five-furcated optical fiber $(5 \times 400 \mu \mathrm{m}$ fiber optic cable, model FC5-UV400-2, Avantes, Eerbeek, Netherlands), and was imaged on the entrance slit of a five-channel spectrometer with spectral coverage from $200 \mathrm{~nm}$ to $844 \mathrm{~nm}$ (model AVS-Rackmount-USB2 housing equipped with five preconfigured AvaSpec-ULS2048USB2-RM channels, Avantes, Apeldoorn, The Netherlands), wherein the plasma light was spectrally resolved and detected. A delay system consisting of two pulse generators (digital delay/ pulse generator, model DG 535, Stanford Research Systems, Inc. and 1-50 MHz pulse/function generator, model 8116A, Hewlett Packard/Agilent Technologies, Santa Clara, USA) was used for synchronization of laser firing and data acquisition. Spectra were obtained $1.3 \mu \mathrm{s}$ after plasma generation, with $1 \mathrm{~ms}$ acquisition time. Cr I (357.869 $\mathrm{nm}$ ) was the emission line evaluated in this study. LIBS spectra were processed using the spectroscopic software LIBS $++\AA$, v. 3.12.4.1., IPCF-CNR (Pisa, Italy).

\subsection{Reagents and solutions}

All solutions were prepared with analytical grade chemicals and deionized water obtained from a Milli-Q system (Millipore, Bedford, USA). A 1.0\% (w/w) DDTC stock solution was prepared daily by dissolving appropriate amounts of reagent $\geq 99.0 \%$ (Sigma Aldrich, St. Louis, USA). Ethanol (Sigma Aldrich, St. Louis, USA) was used as a disperser solvent and 1-undecanol (Acros Organics, Geel, Belgium) as an extractant solvent. Chromium(vi) standard solutions were prepared by appropriate dilutions of $10 \% \mathrm{~K}_{2} \mathrm{CrO}_{4}$ aqueous stock solution (Scharlau, Sentmenat, Spain). Sulfuric acid (Merck, Darmstadt, Germany) and $\mathrm{KMnO}_{4}$ (Scharlau, Sentmenat, Spain) solutions were used for $\mathrm{pH}$ adjustment and as an oxidant reagent, respectively.

\subsection{DLLME procedure and LIBS analysis}

To extract the analyte by DLLME, a fixed amount of sample $(1000 \mathrm{mg})$ or standard solution was transferred to a $10 \mathrm{~mL}$ glass tube.

For $\mathrm{Cr}$ (VI) determination, $522 \mathrm{mg}$ of chelating agent DDTC $1.0 \%(\mathrm{w} / \mathrm{w})$ and $900 \mathrm{mg}$ of $\mathrm{H}_{2} \mathrm{SO}_{4}\left(1.0 \mathrm{~mol} \mathrm{~L}^{-1}\right)$ were added to the sample and the mixture was filled with deionized water up to $9.000 \mathrm{~g}$.

For total Cr determination, after acidification with $900 \mathrm{mg}$ of $1.0 \mathrm{~mol} \mathrm{~L}^{-1} \mathrm{H}_{2} \mathrm{SO}_{4}, 2$ droplets of $0.050 \mathrm{~mol} \mathrm{~L}^{-1} \mathrm{KMnO}_{4}$ solution were added. The resulting mixture was heated at $45{ }^{\circ} \mathrm{C}$ for 15 minutes to ensure the oxidation of Cr species. ${ }^{15}$ After cooling, $522 \mathrm{mg}$ of chelating agent DDTC $1.0 \%(\mathrm{w} / \mathrm{w})$ was added and the mixture was filled with deionized water up to $9.000 \mathrm{~g}$.

After the steps described above, with the aim of either $\mathrm{Cr}(\mathrm{vI})$ or total Cr determination, a mixture of $50 \mu \mathrm{L}$ of extractant solvent (1-undecanol) and $156 \mu \mathrm{L}$ of disperser solvent (ethanol) was injected into the sample using a glass syringe. Phase separation was then achieved by centrifugation at $3000 \mathrm{rpm}$ for $3 \mathrm{~min}$.

LIBS analysis of the resulting analyte-enriched organic solvent was carried out using the surface-enhanced LIBS methodology (SENLIBS) already described elsewhere. ${ }^{16-20}$ To this end, $10 \mu \mathrm{L}$ of the organic extract was transferred to an aluminum substrate, heated to dryness and analyzed by the LIBS experimental system described above (Section 2.1).

The Cr(III) concentration in the samples was evaluated from the difference between the total $\mathrm{Cr}$ and $\mathrm{Cr}(\mathrm{vI})$ concentrations found using the above mentioned procedure.

\subsection{Optimization of DLLME experimental parameters}

The DLLME procedure was optimized by multivariate analysis consisting of two steps: (i) a Plackett-Burman design 
(screening) followed by (ii) a Circumscribed Central Composite Design (CCCD) (optimization) using the NemrodW statistical software (NemrodW® v.2007/2010, LPRAI, Marseille, France). Each step involved 12 microextraction experiments, which were carried out randomly to minimize the effect of uncontrollable variances. The optimization studies were carried out using a standard solution containing $500 \mu \mathrm{g} \mathrm{kg}^{-1} \mathrm{Cr}(\mathrm{vI})$ in deionized water. A LIBS emission signal obtained from the analysis of the organic solvents resulting from the microextraction procedures was used as a response variable.

\section{Results and discussion}

\subsection{Optimization of experimental parameters}

Table 1 shows the experimental factors and levels used in the exploratory planning, leading to a matrix with 12 experiments (Plackett-Burman design). The results obtained from this screening study are shown in the Pareto chart in Fig. 1(a). In this chart, bars to the right indicate a positive influence on the DLLME procedure when increasing the value of the experimental factor, whereas bars to the left indicate a negative influence. The two vertical lines refer to the reliability level of 95\% and the factors with a significant influence on the DLLME procedure go beyond these lines. As observed, the $\mathrm{H}_{2} \mathrm{SO}_{4}$ concentration and extractant solvent volume do not have a significant influence on DLLME. Therefore, we decided to maintain the $\mathrm{H}_{2} \mathrm{SO}_{4}$ concentration at $0.10 \mathrm{~mol} \mathrm{~L}^{-1}$ and the 1-undecanol volume at $50 \mu \mathrm{L}$. On the other hand, the DDTC concentration seems to be an important factor with respect to $\mathrm{Cr}(\mathrm{vI})$ microextraction and increasing its concentration is beneficial to DLLME.

The volume of disperser solvent was a factor that did not go beyond the reference line but remained close to it. For this reason, the disperser solvent volume was also investigated in

Table 1 Experimental factors and levels of the Plackett-Burman and Circumscribed Central Composite Design (CCCD)

\begin{tabular}{lll} 
Plackett-Burman & & \\
\hline & Level & \\
Experimental factor & Low $(-1)$ & High $(+1)$ \\
\hline $\mathrm{H}_{2} \mathrm{SO}_{4} /\left(\mathrm{mol} \mathrm{L}^{-1}\right)$ & 0.01 & 0.1 \\
{$[\mathrm{DDTC}] /(\%, \mathrm{w} / \mathrm{w})$} & 0.01 & 0.1 \\
Disperser volume $/(\mu \mathrm{L})$ & 100 & 200 \\
Extractant volume $/(\mu \mathrm{L})$ & 50 & 100 \\
\hline
\end{tabular}

Circumscribed central composite design

\begin{tabular}{llllllll}
\hline & & & & \multicolumn{2}{l}{$\begin{array}{l}\text { Star points } \\
(\alpha=1.4142)\end{array}$} \\
\cline { 2 - 4 } Experimental factor & Low $(-1)$ & Central $(0)$ & High $(+1)$ & $-\alpha$ & $+\alpha$ \\
\hline$[\mathrm{DDTC}] /(\%, \mathrm{w} / \mathrm{w})$ & 0.020 & 0.055 & 0.090 & & 0.0055 & 0.105 \\
Disperser volume $/(\mu \mathrm{L})$ & 114 & 150 & 185 & & 100 & 200
\end{tabular}

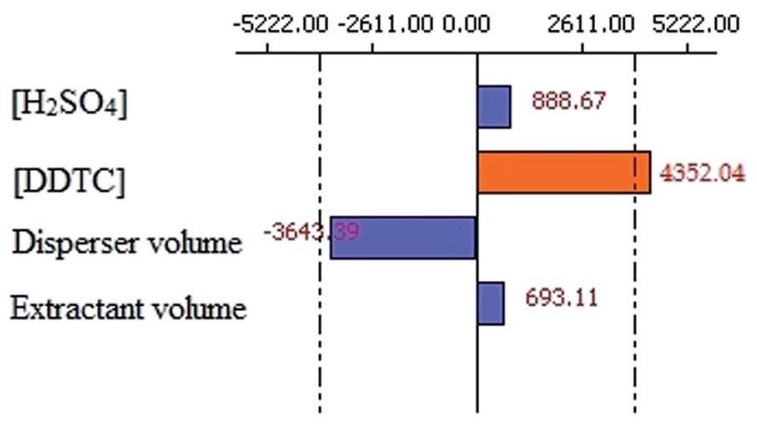

(a)

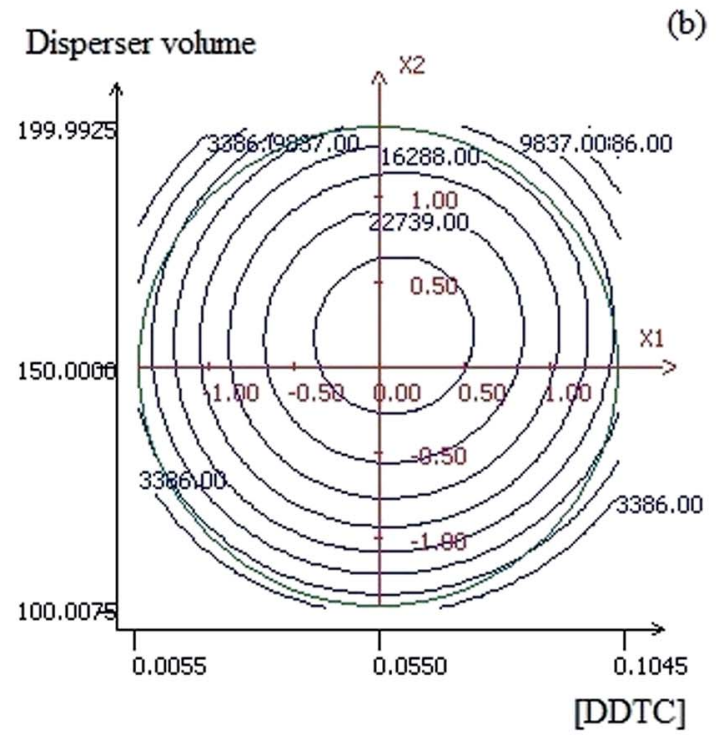

(c)

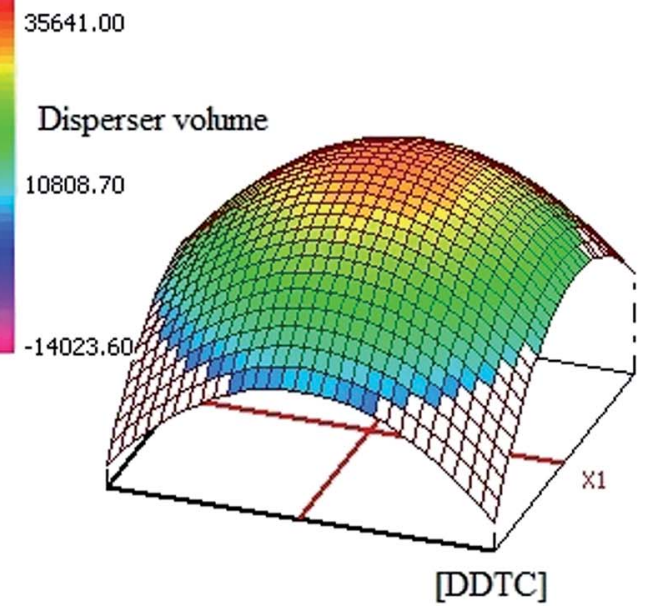

Fig. 1 (a) Pareto charts obtained in the screening study of the experimental factors affecting the DLLME of $\mathrm{Cr}(\mathrm{vI})$; (b) Contour plot and (c) response surface from circumscribed central composite design.

the following step. The DDTC concentration and disperser solvent volume were studied at five levels using a Circumscribed Central Composite Design (CCCD). Table 1 shows various levels selected in the CCCD, leading to a matrix with 12 experiments 
based on 4 repetitions of the central point. The results of this study are given in Fig. 1(b) and (c) as a contour plot and a response surface, respectively, showing the variation in the LIBS emission signal as a function of DDTC concentration and disperser solvent volume.

It can be observed in Fig. 1(b) that the disperser solvent volume and DDTC concentration meet an optimal value for $\mathrm{Cr}(\mathrm{vI})$ extraction at $156 \mu \mathrm{L}$ and $0.058 \%(\mathrm{w} / \mathrm{w})$, respectively. The quantity of DDTC added to the sample should be high enough to ensure quantitative complexation of the analyte. In general, an excess is necessary to guarantee the formation of a fair amount of the target analyte complex, even in the presence of interfering species. ${ }^{\mathbf{2 0 - 2 2}}$ The volume of disperser solvent should be controlled to ensure adequate extractant solvent dispersion, thus leading to the formation of fine droplets that are responsible for the extraction efficiency in DLLME. However, an excess of disperser solvent may increase the solubility of the previously formed hydrophobic analyte complex in the aqueous phase and the dilution of the organic phase, thus resulting in a lower extraction efficiency.

Based on the results shown above, the DLLME experimental conditions selected for chromium speciation were: DDTC concentration $0.058 \%(\mathrm{w} / \mathrm{w}), \mathrm{H}_{2} \mathrm{SO}_{4}$ concentration $0.10 \mathrm{~mol} \mathrm{~L}^{-1}$, $50 \mu \mathrm{L}$ of 1 -undecanol as extractant solvent and $156 \mu \mathrm{L}$ of ethanol as disperser solvent.

\subsection{Analytical figures of merit: LIBS and DLLME-LIBS}

Analytical figures of merit of the DLLME-LIBS methodology (i.e. sensitivity, limit of detection (LOD), limit of quantification (LOQ) and repeatability) were evaluated to assess the analytical capability of this procedure with respect to determination of $\mathrm{Cr}$ in water samples. In addition, analytical figures of merit characterizing the direct LIBS analysis of the aqueous samples for $\mathrm{Cr}$ determination (i.e. LIBS analysis of the samples without applying the DLLME procedure prior to LIBS detection) were also evaluated, with the aim of assessing the advantages provided by the use of the proposed preconcentration step for quantification of $\mathrm{Cr}$ by the LIBS technique.

Calibration curves were obtained, in triplicate, with both LIBS and DLLME-LIBS methodologies. In the DLLME-LIBS methodology, $\operatorname{Cr}(\mathrm{vI})$ was extracted from five aqueous calibration standard solutions with concentrations increasing up to $300 \mu \mathrm{g} \mathrm{kg}^{-1}$. Afterward, the analyte-enriched solvents resulting from the extractions were analysed by LIBS as indicated in Section 2.1, that is, $10 \mu \mathrm{L}$ of solvent were placed on an aluminum substrate, heated to dryness and analysed by LIBS. In the LIBS methodology, calibration was performed by analyzing five $\mathrm{Cr}(\mathrm{vI})$ aqueous calibration standards with concentrations increasing up to $1000 \mu \mathrm{g} \mathrm{kg}^{-1}$. In this case, however, $10 \mu \mathrm{L}$ of each aqueous standard were directly heated to dryness on the aluminium substrate and were analysed by LIBS (i.e. without any previous microextraction step). In all cases, LIBS analysis was carried out by averaging the LIBS signal obtained from four single laser shots in different positions on the same dry residue.

Table 2 shows the analytical figures of merit of both LIBS and DLLME-LIBS procedures. Sensitivity was derived from the slope
Table 2 Analytical figures of merit of LIBS and DLLME-LIBS methods for $\mathrm{Cr}$ determination

\begin{tabular}{|c|c|c|}
\hline \multirow[b]{2}{*}{ Parameters } & \multicolumn{2}{|c|}{ Cr I (357.869 nm) } \\
\hline & LIBS & DLLME-LIBS \\
\hline Linear range $/\left(\mu \mathrm{g} \mathrm{kg}{ }^{-1}\right)$ & $0.0-1000$ & $0.0-300$ \\
\hline$R^{2 a}$ & 0.9741 & 0.9859 \\
\hline Sensitivity/(cts $\left.\mathrm{kg} \mu \mathrm{g}^{-1}\right)^{a, b}$ & $6.4 \pm 3.3$ & $204 \pm 74$ \\
\hline $\mathrm{LOD} /(\mu \mathrm{g} \mathrm{kg}-1)$ & 68 & 3.1 \\
\hline $\mathrm{LOQ} /\left(\mu \mathrm{g} \mathrm{kg}{ }^{-1}\right)$ & 227 & 10 \\
\hline Repeatability $\left(\mathrm{RSD}^{2}\right)^{c}$ & 17 & 18 \\
\hline Relative sensitivity ${ }^{d}$ & & \\
\hline \multicolumn{3}{|c|}{$\begin{array}{l}{ }^{a} \text { Number of calibration points, } n=5 \cdot{ }^{b} \text { Value } \pm \text { standard deviation. } \\
{ }^{c} \text { Relative standard deviation, } n=10 \text {, [Cr(vI)] } 800 \mu \mathrm{kg}^{-1} \text { (LIBS) and } \\
200 \mu \mathrm{g} \mathrm{kg}{ }^{-1} \text { (DLLME-LIBS). }{ }^{d} \text { Sensitivity of DLLME-LIBS/sensitivity of } \\
\text { LIBS. }\end{array}$} \\
\hline
\end{tabular}

of the calibration graphs. The LOD calculation was based on three times the standard deviation of ten blank determinations (deionized water for LIBS and 1-undecanol for DLLME-LIBS), whereas the LOQ was based on ten times the standard deviation of ten blank determinations. Repeatability (RSD, relative standard deviation) was estimated from 10 independent measurements (i.e. ten independent extractions of a $200 \mu \mathrm{g} \mathrm{kg}{ }^{-1} \mathrm{Cr}(\mathrm{vI})$ standard solution followed by LIBS detection of the resulting analyte-enriched solvents) by DLLME-LIBS and 10 independent measurements of a $800 \mu \mathrm{g} \mathrm{kg}^{-1} \mathrm{Cr}(\mathrm{vI})$ standard solution in deionized water by LIBS.

As can be observed, the use of the DLLME procedure prior to LIBS analysis (DLLME-LIBS method) results in a 32-fold increase in sensitivity compared to the direct LIBS analysis of the solutions (LIBS method). Such a high increase in sensitivity leads to about a 22-fold decrease in the detection and quantification limits compared to the LIBS method, the LOD and LOQ being $3.1 \mu \mathrm{g} \mathrm{kg}^{-1}$ and $10 \mu \mathrm{g} \mathrm{kg}{ }^{-1}$, respectively, obtained with DLLME-LIBS methodology.

\subsection{Analysis of a certified reference material}

The method accuracy was evaluated from the analysis of a certified reference material of hard drinking water CRM (ERM ${ }^{\circledR} \mathrm{CA011a}$ ) containing $\mathrm{Ca}, \mathrm{Mg}, \mathrm{K}$ and $\mathrm{Na}$ as majority elements, with concentrations ranging from about 5 to $90 \mathrm{mg}$ $\mathrm{kg}^{-1}$, depending on the element, and many other minority concomitant metals ( $\mathrm{Zn}, \mathrm{Ni}, \mathrm{Mn}, \mathrm{Pb}, \mathrm{Fe}, \mathrm{Cu}, \mathrm{Cd}$, and $\mathrm{Al}$ ) in concentrations ranging from about 5 to $2000 \mu \mathrm{g} \mathrm{kg}^{-1}$. From this analysis, the $\mathrm{Cr}$ in the sample was found to be $44 \pm 7 \mu \mathrm{g} \mathrm{kg}{ }^{-1}$ in the form of $\mathrm{Cr}$ (III), which was in good agreement with the certified value ( $48 \pm 3 \mu \mathrm{g} \mathrm{kg}^{-1}$ ). Percent recovery, calculated by comparison with the $\mathrm{Cr}$ (III) certified value, was $92 \pm 14 \%$. From this result, it can be argued that, at least for samples with matrix compositions similar to that of the analyzed CRM, no matrix effects resulting from the presence of concomitant metals seem to influence quantification of $\mathrm{Cr}$.

The low precision obtained in the analysis, as already pointed out elsewhere, ${ }^{19}$ can be mainly attributed to the low 
repeatability of the LIBS measurement. Samples are heated to dryness on an aluminum substrate prior to LIBS analysis, which results in an inhomogeneous distribution of the analyte on the dry residue being interrogated by the laser, and thus a low repeatability even for replicate LIBS measurements performed at different positions on the same residue. This inconvenience can be solved using a different strategy for the predictable and homogeneous deposition of the liquid sample on the aluminum substrate, which is currently being performed in our laboratory with very promising results.

Determination of the $\mathrm{Cr}$ in different samples after extraction procedures, such as cloud point extraction (CPE), DLLME, ultrasound-assisted DLLME, ionic liquid DLLME, salt-assisted liquid-liquid microextraction with ionic liquid (SALLME-IL), solidified floating organic drop microextraction (SFODME) or hollow fiber liquid phase microextraction (HF-LPME), combined with spectrometric techniques has also been carried out by other authors. ${ }^{2,15,23-27}$ As shown in Table 3, a procedure combining LIBS with DLLME leads to detection limits of the same order than the ones obtained using different instrumental techniques, except in the case of GFAAS detection, as expected. The DLLME procedure proposed in this study is simple, avoiding the solidification step to separate the analyte-enriched organic drop from the aqueous solution, the magnetic stirring for organic dispersion and the heating step commonly needed in CPE. In addition, the simple and compact LIBS instrumentation, when compared to the more complicated and voluminous FAAS, GFAAS or ICP-OES equipment, can be considered a very attractive feature characterizing the proposed DLLME-LIBS methodology, being a further step toward the development of analytical methodologies that can be performed in miniaturized and portable systems for in-field early-warning and monitoring.

A number of different liquid phase microextraction (LPME) procedures have already been used by our group to increase the LIBS sensitivity for liquid sample analysis. ${ }^{16-20}$ A single drop microextraction procedure (SDME), using APDC (pyrrolidinedithiocarbamate) as a complexing agent and toluene as an extractant solvent, was combined with LIBS detection for the quantification of $\mathrm{Cr}, \mathrm{Cu}, \mathrm{Mn}, \mathrm{Ni}$ and $\mathrm{Zn}$ in water samples. ${ }^{19}$ The SDME-LIBS method resulted in a 2.5 -fold increase in sensitivity and a 2.9-fold decrease in the LOD when compared to the direct LIBS analysis of the samples for $\mathrm{Cr}$ determination (LIBS method). The same metals were analyzed using the combination of DLLME with LIBS (DLLME-LIBS). ${ }^{18}$ In this study, using APDC and tetrachloromethane as complexing agent and extractant solvent, respectively, the sensitivity and the LOD for Cr determination were further improved (i.e. 4.8 and 4.5 times, respectively, as obtained with the LIBS method).

Table 3 Comparison of the proposed method with other extraction methods for $\mathrm{Cr}$ speciation in water samples ${ }^{a}$

\begin{tabular}{|c|c|c|c|}
\hline $\begin{array}{l}\text { Dispersive liquid-liquid microextraction } \\
\text { (DLLME)/FAAS }\end{array}$ & $\begin{array}{l}\text { Chelating reagent: APDC } \\
\text { Extractant solvent: carbon tetrachloride, } 60 \mu \mathrm{L} \\
\text { Disperser solvent: ethanol, } 2.00 \mathrm{~mL}\end{array}$ & $\begin{array}{l}0.07 \mu \mathrm{g} \mathrm{L}^{-1}(\mathrm{Cr}(\mathrm{vI})) \\
0.08 \mu \mathrm{g} \mathrm{L}^{-1}\left(\mathrm{Cr}_{\text {total }}\right)\end{array}$ & 2 \\
\hline
\end{tabular}
Sample volume: $25 \mathrm{~mL}$

Salt-assisted liquid-liquid microextraction with ionic liquid (SALLME-IL)/FAAS

Ionic liquid dispersive liquid-liquid microextraction (IL-DLLME)/GFAAS

Solidified floating organic drop microextraction (SFODME)/GFAAS

Cloud point extraction (CPE)/ICP-OES

Dispersive liquid-liquid microextraction (DLLME)/LIBS
Chelating reagent: DPC

Extractant solvent: $\left[\mathrm{C}_{4} \mathrm{mim}\right]\left[\mathrm{BF}_{4}\right], 150 \mu \mathrm{L}$

Oxidant reagent: $\mathrm{KMnO}_{4}$

Sample volume: $10 \mathrm{~mL}$

Chelating reagent: APDC

Extractant solvent: $\left[\mathrm{C}_{8} \mathrm{MIm}\right]\left[\mathrm{NTf}_{2}\right], 33 \mu \mathrm{L}$

Sample volume: $10 \mathrm{~mL}$

Chelating reagent: TTA

Extractant solvent: 1-undecanol, $30 \mu \mathrm{L}$ Reducing reagent: hydroxylamine hydrochloride Sample volume: $10 \mathrm{~mL}$

Chelating reagent: PMBP

Surfactant: triton X-100, $1.0 \mathrm{~mL}$

Reducing reagent: ascorbic acid

Sample volume: $10 \mathrm{~mL}$

Chelating reagent: DDTC

Extractant solvent: 1-undecanol, $50 \mu \mathrm{L}$

Disperser solvent: ethanol, $156 \mu \mathrm{L}$

Oxidant reagent: $\mathrm{KMnO}_{4}$

Sample volume: $9 \mathrm{~mL}$
25

$1.25 \mu \mathrm{g} \mathrm{L}^{-1}$

15

$2 n g \mathrm{~L}^{-1}$

23

$0.81 \mu \mathrm{g} \mathrm{L} \mathrm{L}^{-1}$

26

$3.1 \mu \mathrm{g} \mathrm{kg}{ }^{-1}$

This work

\footnotetext{
${ }^{a}$ APDC: ammonium pyrrolidinedithiocarbamate; DPC 1,5-diphenylcarbazide; $\left[\mathrm{C}_{4} \mathrm{mim}\right]\left[\mathrm{BF}_{4}\right]$ 1-butyl-3-methylimidazolium tetrafluoroborate; $\left[\mathrm{C}_{8} \mathrm{MIm}\right]\left[\mathrm{NTf}_{2}\right]$ 1-octyl-3-methylimidazolium bis(trifluoromethanesulfonyl)imide; TTA 2-thenoyltrifluoroacetone; PMBP 1-phenyl-3-methyl-4benzoylpyrazol-5-one.
} 
The DLLME-LIBS method proposed in this study is a significant improvement on previous methods with respect to $\mathrm{Cr}$ quantification, ${ }^{\mathbf{1 8 , 1 9}}$ showing that adequate selection of the microextraction procedure to be used prior to LIBS detection, along with working conditions (e.g. complexing agent and extractant solvent) are critical in improving the analytical performance of this spectrometric technique for liquid sample analysis. In this study, the use of DDTC as a complexing agent was based on the previous study proposed by Yanagisawa et $a l .{ }^{28}$ which demonstrated the possibility of Cr speciation by selective extraction of $\mathrm{Cr}(\mathrm{vI})$ in an acidic medium. However, DPC (1,5-diphenylcarbazide) is the most frequently used complexing agent for $\mathrm{Cr}(\mathrm{vI})$ determination and is also recommended by the US Environmental Protection Agency (EPA methods 7196a and 218.7) and the International Organization for Standardization (ISO 11083). As an example, Balasubramanian and Pugalenthi ${ }^{29}$ proposed the determination of total Cr by ICP-OES, FAAS and UV-visible spectrophotometry methods. With the use of DPC as a colorimetric agent for the spectrophotometric method, the authors obtained a detection limit of $5 \mu \mathrm{g} \mathrm{\textrm {L } ^ { - 1 }}$. Because studies on different and more efficient microextraction conditions are currently in process by our research group, to further improve the analytical capabilities of LPME-LIBS methodologies, a comparison between DPC and substituted dithiocarbamates as complexing agents for Cr speciation by DLLME-LIBS procedures seems to be an unavoidable next step.

\section{Conclusions}

For certain type of samples, such as those of environmental interest, determination of the total content of some metals is frequently insufficient to correlate metal concentration to possible toxicological effects or environmental risks, especially for those metals displaying different behavior depending on their oxidation state such as $\mathrm{Cr}(\mathrm{III})$ and $\mathrm{Cr}(\mathrm{VI})$ ions. The combination of microextraction procedures, which not only makes possible speciation but also analyte preconcentration, with spectrometric detection techniques, has therefore been of particular interest over the last few years for metal speciation purposes.

The study presented here is a breakthrough in hyphenating a microextraction procedure based on DLLME modality with LIBS detection for speciation and determination of $\mathrm{Cr}$ at low concentrations in liquid samples. The DLLME-LIBS methodology developed in this study allows not only speciation of $\mathrm{Cr}$ but also quantification of this element at a concentration level as low as $10 \mu \mathrm{g} \mathrm{kg}^{-1}$. This LOD value is well below the level of concentration established by the Environmental Protection Agency (EPA), $100 \mu \mathrm{g} \mathrm{L}^{-1},{ }^{30}$ or the European Drinking Water Directive of The European Union Council (EUC), $50 \mu \mathrm{g} \mathrm{L}^{-1},{ }^{31}$ for Cr in drinking water.

Compared to direct LIBS analysis of the samples (i.e. LIBS method), the addition of the proposed DLLME step for analyte enrichment prior to spectroscopic measurement improves sensitivity by a factor of 32 and decreases the LOD and LOQ by a factor of 22. These results represent great progress over studies previously performed with the aim of improving the analytical capability of LIBS by hyphenation with microextraction procedures. ${ }^{\mathbf{1 8 , 1 9}}$ However, as in previous study, the low repeatability of the LIBS measurement step is still the limiting factor with respect to improving the method accuracy. Studies on new ways of preparing the micro-samples for reproducible LIBS measurements are currently being performed by our research group, to overcome this inconvenience. Therefore, further improvements can be expected by continuing this research line, focusing on the hyphenation of LPME methodologies with LIBS detection (LPME-LIB).

\section{Acknowledgements}

National Council for Scientific and Technological Development (Brazil) (CNPq - Science without Borders project no. 245782/ 2012-5) and São Paulo Foundation Research (FAPESP project no. 2011/19730-3) are acknowledged. This study has been supported by the Government of Spain (CTQ2011-23968) and the Regional Government of Valencia (Spain) (ACOMP/2013/072).

\section{References}

1 N. Unceta, F. Séby, J. Malherbe and O. F. X. Donard, Anal. Bioanal. Chem., 2010, 397, 1097.

2 P. Hemmatkhah, A. Bidari, S. Jafarvand, M. R. M. Hosseini and Y. Assadi, Microchim. Acta, 2009, 166, 69.

3 L. Hua, Y. C. Chan, Y. P. Wu and B. Y. Wu, J. Hazard. Mater., 2009, 163, 1360.

4 J. Kotas and Z. Stasicka, Environ. Pollut., 2000, 107, 263.

5 D. Dinda and S. K. Saha, J. Hazard. Mater., 2015, 291, 93.

6 D. A. Eastmond, J. T. MacGregor and R. S. Slesinski, Crit. Rev. Toxicol., 2008, 38, 173.

7 U.S. Environmental Protection Agency, Toxicological review of hexavalent chromium, Washington, DC, 1998, Last access in 07/03/2015, http:/www.epa.gov/iris/toxreviews/0144tr.pdf.

8 U.S. Department of Health and Human Services, Public Health Service Agency for Toxic Substances and Disease Registry, Toxicological profiles for chromium, Last access in 07/03/2015, http://www.atsdr.cdc.gov/toxprofiles/tp7.pdf.

9 P. M. Outridge and A. M. Scheuhammer, Rev. Environ. Contam. Toxicol., 1993, 130, 31.

10 B. Markiewicz, I. Komorowicz, A. Sajnóg, M. Belter and D. Barałkiewicz, Talanta, 2015, 132, 814.

11 V. Gómez and M. P. Callao, TrAC, Trends Anal. Chem., 2006, 25, 1006.

12 A. L. Rosen and G. M. Hieftje, Spectrochim. Acta, Part B, 2004, 59, 135.

13 C. R. Dockery, J. E. Pender and S. R. Goode, Appl. Spectrosc., 2005, 59, 252.

14 V. Andruch, I. S. Balogh, L. Kocúrová and J. Sandrejová, J. Anal. At. Spectrom., 2013, 28, 19.

15 B. Majidi and F. Shemirani, Microchim. Acta, 2012, 176, 143. 16 M. A. Aguirre, S. Legnaioli, F. Almodóvar, M. Hidalgo, V. Palleschi and A. Canals, Spectrochim. Acta, Part B, 2013, 79, 88.

17 A. M. Jesus, M. A. A. Pastor, M. Hidalgo, A. Canals and E. R. Pereira-Filho, J. Anal. At. Spectrom., 2014, 29, 1813. 
18 M. A. Aguirre, E. J. Selva, M. Hidalgo and A. Canals, Talanta, 2015, 131, 348.

19 M. A. Aguirre, H. Nikolova, M. Hidalgo and A. Canals, Anal. Methods, 2015, 7, 877.

20 I. Gaubeur, M. A. Aguirre, N. Kovachev, M. Hidalgo and A. Canals, Microchem. J., 2015, 121, 219.

21 R. Galbeiro, S. Garcia and I. Gaubeur, J. Trace Elem. Med. Biol., 2014, 28, 160.

22 S. Garcia, F. Gerondi, T. R. L. C. Paixão, M. A. Z. Arruda and I. Gaubeur, J. Braz. Chem. Soc., 2015, 26, 490.

23 I. López-García, Y. Vicente-Martínez and M. HernándezCórdoba, J. Anal. At. Spectrom., 2012, 27, 874.

24 I. López-García, M. Briceño, Y. Vicente-Martínez and M. Hernández-Córdoba, Talanta, 2013, 115, 166.

25 M. R. Moghadam, S. Dadfarnia and A. M. H. Shabani, J. Hazard. Mater., 2011, 186, 169.
26 P. Liang and J. Li, At. Spectrosc., 2005, 26, 89.

27 C. Zeng, Y. Lin, N. Zhou, J. Zheng and W. Zhang, J. Hazard. Mater., 2012, 237, 365.

28 M. Yanagisawa, M. Suzuki and T. Takeuchi, Microchim. Acta, 1973, 61, 475.

29 S. Balasubramanian and V. Pugalenthi, Talanta, 1999, 50, 457.

30 United States Environmental Protection Agency, Water: Chromium in drinking water, Last access in 7/18/2015, http:/water.epa.gov/drink/info/chromium/index.cfm.

31 Council Directive 98/83/EC. of 3 November 1998 on the quality of water intended for human consumption, Off. J. Eur. Communities L 330 (05/12/1998) 0032-0054 Last access in 1/06/2015, http:/ec.europa.eu/environment/ water/water-drink/legislation_en.html. 